\title{
EXPERIMENTAL AND FINITE ELEMENT STUDIES ON FREE VIBRATION OF SKEW PLATES
}

\author{
C.V. SRINIVASA* \\ Department of Mechanical Engineering \\ GM Institute of Technology \\ Davangere, Karnataka, INDIA-577006 \\ E-mails: srinikanadamani@gmail.com; srinivas@gmit.info \\ Y.J. SURESH \\ Department of Mechanical Engineering \\ J.N.N. College of Engineering \\ Shivamogga, Karnataka, INDIA-577204 \\ E-mail: yjsuresh06@gmail.com \\ W.P. PREMA KUMAR \\ Department of Civil Engineering \\ Reva Institute of Technology and Management \\ Bangalore, Karnataka, INDIA-560064 \\ E-mail: wppremakumar@yahoo.co.in
}

\begin{abstract}
The present paper deals with the experimental studies carried out on free vibration of isotropic and laminated composite skew plates. The natural frequencies were also determined using QUAD8 finite element of MSC/NASTRAN and a comparison was made between the experimental values and the finite element solution. The effects of the skew angle and aspect ratio on the natural frequencies of isotropic skew plates were studied. The effects of the skew angle, aspect ratio, fiber orientation angle and laminate sequence (keeping the number of layers constant) on the natural frequencies of antisymmetric composite laminates were also studied. The experimental values of natural frequencies are in good agreement with the FE solutions. The natural frequencies are found to increase with an increase in the skew angle. The variation of natural frequencies with the aspect ratio is small and negligible both for isotropic and laminated composite skew plates.
\end{abstract}

Key words: skew plates, antisymmetric laminates, free vibration, experimental method, finite element analysis.

\section{Introduction}

Skew plates find a wide range of applications in civil, marine, aeronautical and mechanical engineering, the common applications being swept wings of aeroplanes, skew bridge design, ship hulls and parallelogram slabs in buildings. The exact solutions to skew plate vibration problems are mathematically difficult and hence most of the solutions available in the literature are based on approximate methods. Over the past four decades, a lot of research has been carried out on the study of vibration characteristics of skew plates. Today the skew plate problem has been widely recognised as a benchmark in the testing of a newly developed finite element.

\footnotetext{
* To whom correspondence should be addressed
} 
The earlier studies on free vibration characteristics of skew plates are those of Barton (1951), Kaul and Cadambe (1956) and Hasegawa (1957) using Rayleigh-Ritz method. Hamada (1959) applied the Lagrangian-multiplier method to obtain the fundamental frequency of rhombic skew plates. Claassen (1963) extended the work of Barton (1951) by adopting a Fourier sine series solution scheme in conjunction with the Rayleigh-Ritz method. Conway and Farnham (1965) employed the point matching method to study the free vibration of triangular, rhombic and parallelogram plates. The frequencies were calculated for different skew angles of simply supported and clamped boundary conditions. Laura and Grosson (1968) obtained fundamental frequencies of vibration for simply supported rhombic plates using conformal mapping and Galerkin's method and compared their results with those of Conway and Farnham (1965). The discrepancy has been found to increase with the skew angle.

Monforton (1968) obtained fundamental frequencies of clamped rhombic plates by using the FEM. The frequencies and mode shapes of clamped skew plates were studied by Durvasula (1969) using Galerkin's method. The deflection function was expressed as a double series of beam characteristic functions in terms of skew coordinates to satisfy the zero deflection and normal slope on all the edges. Some interesting results were obtained and compared with the results of Kaul and Cadambe (1956), Hasegawa (1957) and Conway and Farnham (1965). Thangam Babu and Reddy (1971) investigated the free vibration of orthotropic skew plates with two opposite edges simply supported and the other two edges free. Nair and Durvasula (1973) reported the frequencies of isotropic and orthotropic skew plates for the simply supported, clamped, free edge boundary condition and for a combination of the above three edge conditions. Srinivasan and Ramachandran (1975) employed a numerical method to study variations of frequencies and mode shapes of orthotropic skew plates. Kuttler and Sigillito (1980) used trial function method to solve the vibration problem of skew plates.

Mizusuwa et al. (1979; 1980), Mizusuwa and Kajita (1986; 1987) employed the Rayleigh-Ritz method with B-spline functions to study the effect of skew angle and location of point supports on natural frequencies of isotropic skew plates. Liew and Lam (1990) used a set of 2-D orthogonal plate functions as an admissible deflection function to study the flexural vibration of skew plates using Rayleigh-Ritz method and obtained the results for four rhombic plates with different support conditions. Bardell (1992) adopted the hierarchical finite element method to determine natural frequencies and mode shapes of isotropic skew plates. Liew and Wang (1993) employed the Rayleigh-Ritz method and obtained results for four rhombic plates with different support conditions by changing the internal support, skew angle and aspect ratio. Singh and Chakravarthy (1994) evaluated the first five frequencies for the transverse vibration of skew plates under different boundary conditions by using boundary characteristics orthogonal polynomials. McGee and Butalia (1994) studied the free vibration of thick and thin cantilever skew plates using $C^{0}$ continuous isoparametric quadrilateral elements.

Few studies on the free vibration of composite skew plates have been made. Kamal and Durvasula (1986) studied the free vibration characteristics of composite laminates using the modified shear deformation layered composite theory by employing the Rayleigh-Ritz energy approach. Malhotra et al. (1988) studied the rhombic orthotropic plates using a parallelogram orthotropic plate finite element for various boundary conditions and skew angles. Krishnan and Deshpande (1992) employed the DKT finite element to demonstrate the effect of fiber orientation angle, skew angle, aspect ratio and length-to-thickness ratio on the fundamental frequencies of single layer graphite/epoxy and glass/epoxy skew plates.

Krishna Reddy and Palaninathan (1999) used a general high precision triangular bending element to study the free vibration of laminated skew plates. A consistent mass matrix in explicit form is used for the study. Singha and Ganapathi (2004) studied the large amplitude free flexural vibrations of laminated composite skew plates using the FE approach. Garg et al. (2006) carried out free vibration studies on isotropic, orthotropic, and layered anisotropic composite and sandwich skew laminates using the isoparametric finite element model.

Maruyama et al. (1983) used the real time technique of time averaged holographic interferometry to determine the natural frequencies and the corresponding mode shapes for the transverse vibrations of clamped trapezoidal plates. Clary (1975) investigated theoretically and experimentally the effect of fiber orientation on the first five flexural modes of vibration of rectangular, unidirectional, boron-epoxy panels. The agreement between theoretical and experimental frequencies was generally good, though there were large errors in some of the predictions of thinner panels. Cawley and Adams (1978) used the finite element 
method which included transverse shear deformation to predict the natural modes of free-free CFRP plates. Dutt and Shivanand (1978) studied the free vibration response of C-F-F-F and C-F-C-F woven carbon composite laminates using a FFT analyzer and compared with the finite element analysis solution. Chakraborty, et al. (2000) made studies on the free vibration response of FRP composite plates using experimental and numerical techniques. Although a number of researchers have developed several analytical and numerical methods for the determination of natural frequencies of isotropic and laminated composite laminates, few experimental studies on isotropic and laminated composite skew plate structures have been made.

\section{Test specimens and experimental setup}

\subsection{Test specimens}

In this study isotropic plates made of alumina 7075-T6 are used. The material was supplied by the Rio-Tinto Alcon, Canada (Pechiney Aluminum, France). The laminated composite plate specimens were fabricated by hand layup technique using unidirectional glass, epoxy-556 resin and the hardener (HY951) supplied by Ciba-Geigy India Ltd. The ratio of fiber to matrix by weight was taken as 1:1. The appropriate ASTM provisions were followed during the preparation of the test specimens. For each specimen, five trials were made and the average value of frequency is adopted. The materials properties of the plates are: for alumina $7075-\mathrm{T} 6, E=71.7 \mathrm{GPa}, \mu=0.33, \rho=2800 \mathrm{~kg} / \mathrm{m}^{3}$ and for glass-epoxy $E_{1}=38.07 \mathrm{GPa}, E_{2}=8.1 \mathrm{GPa}$, $G 12=3.05 \mathrm{GPa}, v_{12}=0.22, \rho=2200 \mathrm{~kg} / \mathrm{m}^{3}$ and the aspect ratio was varied from 1.0 to 2.5 .

\subsection{Experimental setup}

The experimental set-up is shown in Fig.1. The fixture shown in Fig.1 provides clamped-edgecondition for two opposite edges in one direction and free-edge-condition for the other two opposite edges. An impact hammer was used to give the input pulse to the specimen and precautions were taken for ensuring that the stroke is normal to the surface of the plate. The first three natural frequency responses were captured by means of accelerometer placed at the geometric centre of the plate. The response signal was acquired using the FFT (Fast Fourier Transform) analyzer which was later amplified using a conditioning amplifier and then read using a high resolution signal analyzer giving on FRF (Frequency Response Function).

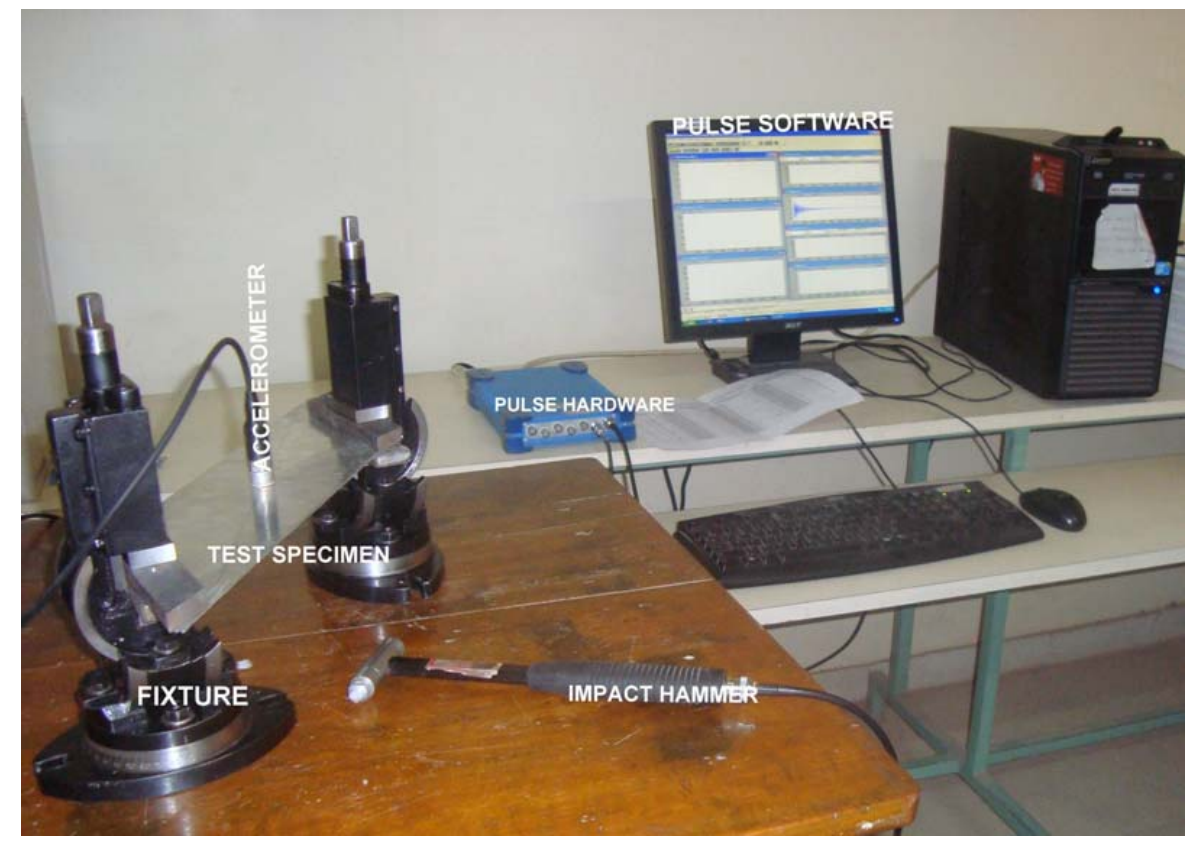

Fig.1. Experimental set-up. 


\section{Finite element solution}

A finite element analysis was made for obtaining the first three natural frequencies using MSC/NASTRAN software. CQUAD8 (eight-noded isoparametric curved shell element) was employed as it yields better results compared to CQUAD4 element of the said software as revealed by the investigation reported in Srinivasa et al. (2012).

\section{Results and discussions}

The results of the present work are presented in terms of the non-dimensional frequency coefficient $\left(K_{f}\right)$ defined by $K_{f}=\frac{\omega a^{2}}{\pi^{2}} \sqrt{\frac{\rho t}{D}}$ for isotropic plates and by $K_{f}=\omega a^{2} \sqrt{\frac{\rho_{l}}{E_{t} t^{3}}}$ for laminated composite plates.

\subsection{Isotropic skew plates}

The thickness of the isotropic skew plates is taken as $2.0 \mathrm{~mm}$. The aspect ratio is varied from 1.0 to 2.5 and the skew angle from $0^{\circ}$ to $45^{\circ}$. Table 1 and Fig.2 show the variation of the non-dimensional frequency coefficient with the aspect ratio and skew angle. The variation of the non-dimensional frequency coefficient (Experimental and FE solution) with the aspect ratio is very small. The non-dimensional frequency coefficient (Experimental and FE solution) increases monotonically with an increase in the skew angle. The experimental values of the frequency coefficient are in very good agreement with FE solutions. The first three mode shapes obtained by FEA are shown in Fig. 3 for the aspect ratio $=1.0$.

Table 1. Non-dimensional frequency coefficients for isotropic skew plates.

\begin{tabular}{|c|c|c|c|c|c|c|c|c|c|}
\hline \multirow{4}{*}{$\begin{array}{l}\text { Aspect ratio } \\
(a / b)\end{array}$} & \multirow{4}{*}{$\begin{array}{l}\text { Mode } \\
\text { number }\end{array}$} & \multicolumn{8}{|c|}{ Non-dimensional frequency coefficients $\left(K_{f}\right)$} \\
\hline & & \multicolumn{8}{|c|}{ Skew angle $(\alpha)$} \\
\hline & & \multicolumn{2}{|c|}{$0^{O}$} & \multicolumn{2}{|c|}{$15^{\mathrm{O}}$} & \multicolumn{2}{|c|}{$30^{\circ}$} & \multicolumn{2}{|c|}{$45^{\circ}$} \\
\hline & & Exp & FEM & Exp & FEM & Exp & FEM & Exp & FEM \\
\hline \multirow{3}{*}{1.0} & 1 & 2.978 & 3.102 & 3.216 & 3.265 & 3.732 & 3.822 & 4.946 & 5.066 \\
\hline & 2 & 3.518 & 3.665 & 3.735 & 3.792 & 4.133 & 4.233 & 5.136 & 5.260 \\
\hline & 3 & 5.795 & 6.036 & 6.123 & 6.216 & 6.708 & 6.870 & 8.383 & 8.585 \\
\hline \multirow{3}{*}{1.5} & 1 & 3.028 & 3.080 & 3.185 & 3.241 & 3.548 & 3.711 & 4.833 & 4.761 \\
\hline & 2 & 4.169 & 4.241 & 4.313 & 4.388 & 4.587 & 4.798 & 5.832 & 5.779 \\
\hline & 3 & 8.343 & 8.487 & 8.817 & 8.970 & 9.519 & 9.957 & 11.483 & 11.361 \\
\hline \multirow{3}{*}{2.0} & 1 & 3.001 & 3.071 & 3.151 & 3.206 & 3.538 & 3.602 & 4.342 & 4.418 \\
\hline & 2 & 4.825 & 4.939 & 5.000 & 5.087 & 5.433 & 5.532 & 6.484 & 6.596 \\
\hline & 3 & 8.270 & 8.465 & 8.747 & 8.898 & 9.998 & 10.180 & 12.554 & 12.771 \\
\hline \multirow{3}{*}{2.5} & 1 & 3.006 & 3.064 & 3.130 & 3.181 & 3.417 & 3.512 & 4.052 & 4.150 \\
\hline & 2 & 5.591 & 5.699 & 5.764 & 5.858 & 6.168 & 6.339 & 7.331 & 7.508 \\
\hline & 3 & 8.281 & 8.442 & 8.709 & 8.850 & 9.749 & 10.019 & 11.972 & 12.260 \\
\hline
\end{tabular}




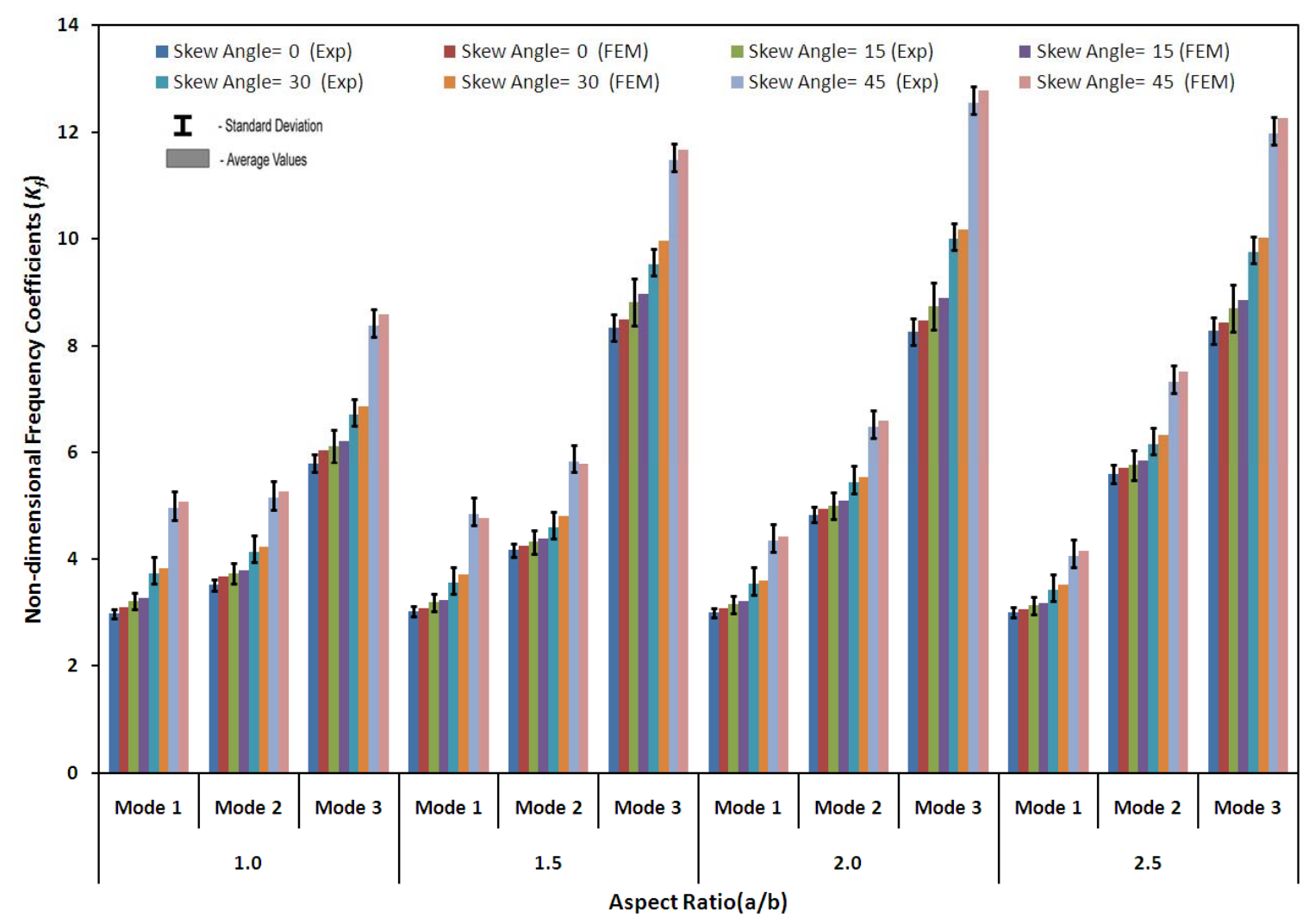

Fig.2. Variations of $K_{f}$ with aspect ratio $(a / b)$ for isotropic skew plates.

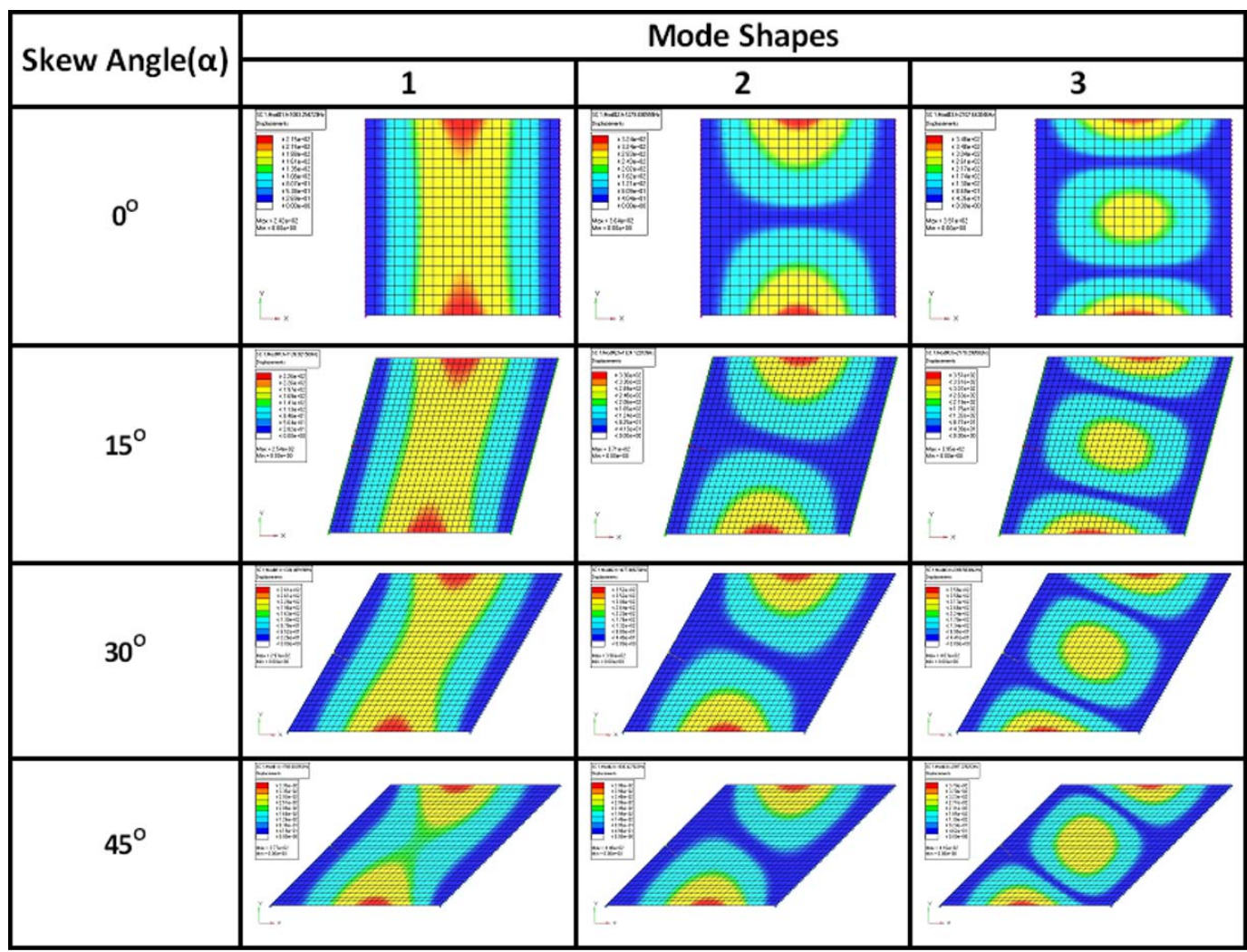

Fig.3. Mode shapes for isotropic skew plates. 


\subsection{Laminated composite skew plates}

The total thickness of the laminate is maintained constant at $2 \mathrm{~mm}$, the number of layers being 20 . The aspect ratio is varied from 1.0 to 2.5 and the skew angle from $0^{\circ}$ to $45^{\circ}$. Tables 2 through 5 , Figs 4 through 7 show the variation of the non-dimensional frequency coefficient with the aspect ratio and stacking sequence for various values of the skew angle equal to $0,15,30$ and 45 degrees, respectively. The stacking sequences of the laminates considered are: antisymmetric cross-ply $0^{\circ} / 90^{\circ}$, antisymmetric angle ply $0^{\circ}$, antisymmetric angle ply $90^{\circ}$ and antisymmetric angle ply $\pm 45^{\circ}$. It is seen that the variation of the first natural frequencies with the aspect ratio is small and negligible for practical purposes. Other parameters being same, antisymmetric angle-ply 0 yields the highest value for the natural frequencies and antisymmetric angle-ply 90 yields the lowest value. The natural frequencies for the other layups lie inbetween the above two extreme values. The natural frequencies increase in magnitude with an increase in the skew angle. The first three mode shapes obtained by FEA are shown in Fig.8 for antisymmetric cross-ply laminates for the aspect ratio $=1.0$.

Table 2. Non-dimensional frequencies of laminated composite skew plate (skew- $\left.0^{\circ}\right)$.

\begin{tabular}{|c|c|c|c|c|c|c|c|c|c|}
\hline \multirow{4}{*}{$\begin{array}{l}\text { Antisymmetric } \\
\text { laminate } \\
\text { sequence }\end{array}$} & \multirow{4}{*}{$\begin{array}{l}\text { Mode } \\
\text { number }\end{array}$} & \multicolumn{8}{|c|}{ Non-dimensional frequency coefficients $\left(K_{f}\right)$} \\
\hline & & \multicolumn{8}{|c|}{ Aspect ratio $(a / b)$} \\
\hline & & \multicolumn{2}{|c|}{1.0} & \multicolumn{2}{|c|}{1.5} & \multicolumn{2}{|c|}{2.0} & \multicolumn{2}{|c|}{2.5} \\
\hline & & Exp & FEM & Exp & FEM & Exp & FEM & Exp & FEM \\
\hline \multirow{3}{*}{ Angle ply $0^{\circ}$} & 1 & 15.304 & 15.617 & 15.180 & 15.649 & 14.983 & 15.607 & 14.824 & 15.604 \\
\hline & 2 & 15.990 & 16.316 & 16.683 & 17.199 & 17.536 & 18.267 & 18.613 & 19.593 \\
\hline & 3 & 19.435 & 19.832 & 26.194 & 27.004 & 36.684 & 38.213 & 40.859 & 43.010 \\
\hline \multirow{3}{*}{ Angle ply $\pm 45^{\circ}$} & 1 & 9.454 & 9.647 & 9.260 & 9.547 & 9.039 & 9.416 & 8.855 & 9.321 \\
\hline & 2 & 12.851 & 13.114 & 15.880 & 16.371 & 19.119 & 19.916 & 22.488 & 23.671 \\
\hline & 3 & 22.684 & 23.147 & 25.673 & 26.467 & 25.069 & 26.114 & 24.548 & 25.840 \\
\hline \multirow{3}{*}{ Angle ply $90^{\circ}$} & 1 & 7.055 & 7.199 & 6.996 & 7.213 & 6.905 & 7.193 & 6.831 & 7.191 \\
\hline & 2 & 8.448 & 8.620 & 9.818 & 10.121 & 11.356 & 11.830 & 13.021 & 13.707 \\
\hline & 3 & 19.399 & 19.795 & 19.283 & 19.879 & 19.031 & 19.824 & 18.827 & 19.818 \\
\hline \multirow{3}{*}{$\begin{array}{l}\text { Cross-ply } \\
0^{\circ} / 90^{\circ}\end{array}$} & 1 & 11.901 & 12.144 & 11.805 & 12.170 & 11.654 & 12.139 & 11.530 & 12.137 \\
\hline & 2 & 12.777 & 13.038 & 13.686 & 14.109 & 14.784 & 15.400 & 16.090 & 16.937 \\
\hline & 3 & 19.420 & 19.817 & 32.410 & 33.412 & 32.120 & 33.458 & 31.780 & 33.452 \\
\hline
\end{tabular}


Table 3. Non-dimensional frequencies of laminated composite skew plate $\left(\right.$ skew- $\left.15^{\circ}\right)$.

\begin{tabular}{|c|c|c|c|c|c|c|c|c|c|}
\hline \multirow{4}{*}{$\begin{array}{l}\text { Antisymmetric } \\
\text { laminate } \\
\text { sequence }\end{array}$} & \multirow{4}{*}{$\begin{array}{l}\text { Mode } \\
\text { number }\end{array}$} & \multicolumn{8}{|c|}{ Non-dimensional frequency coefficients $\left(K_{f}\right)$} \\
\hline & & \multicolumn{8}{|c|}{ Aspect ratio $(a / b)$} \\
\hline & & \multicolumn{2}{|c|}{1.0} & \multicolumn{2}{|c|}{1.5} & \multicolumn{2}{|c|}{2.0} & \multicolumn{2}{|c|}{2.5} \\
\hline & & Exp & FEM & Exp & FEM & Exp & FEM & Exp & FEM \\
\hline \multirow{3}{*}{ Angle ply $0^{\circ}$} & 1 & 15.346 & 15.821 & 15.350 & 15.990 & 14.997 & 15.787 & 14.495 & 15.420 \\
\hline & 2 & 16.103 & 16.602 & 16.502 & 17.190 & 17.739 & 18.672 & 18.852 & 20.056 \\
\hline & 3 & 19.876 & 20.491 & 26.997 & 28.122 & 37.684 & 39.668 & 40.917 & 43.528 \\
\hline \multirow{3}{*}{ Angle ply $\pm 45^{\circ}$} & 1 & 10.235 & 10.552 & 9.688 & 10.092 & 9.498 & 9.998 & 9.253 & 9.844 \\
\hline & 2 & 13.044 & 13.447 & 16.013 & 16.680 & 18.952 & 19.949 & 22.047 & 23.455 \\
\hline & 3 & 22.592 & 23.291 & 26.898 & 28.019 & 27.056 & 28.479 & 25.625 & 27.260 \\
\hline \multirow{3}{*}{ Angle ply $90^{\circ}$} & 1 & 7.368 & 7.596 & 7.253 & 7.556 & 7.107 & 7.481 & 6.976 & 7.421 \\
\hline & 2 & 8.909 & 9.184 & 10.238 & 10.664 & 11.722 & 12.339 & 13.660 & 14.532 \\
\hline & 3 & 18.957 & 19.544 & 20.157 & 20.996 & 19.726 & 20.765 & 19.583 & 20.833 \\
\hline \multirow{3}{*}{$\begin{array}{l}\text { Cross-ply } \\
0^{\circ} / 90^{\circ}\end{array}$} & 1 & 12.032 & 12.404 & 12.099 & 12.603 & 11.740 & 12.358 & 11.480 & 12.212 \\
\hline & 2 & 13.092 & 13.497 & 14.051 & 14.636 & 15.159 & 15.957 & 17.075 & 18.165 \\
\hline & 3 & 20.156 & 20.779 & 31.759 & 33.082 & 32.392 & 34.097 & 32.422 & 34.492 \\
\hline
\end{tabular}

Table 4. Non-dimensional frequencies of laminated composite skew plate (skew-35 $)$.

\begin{tabular}{|c|c|c|c|c|c|c|c|c|c|}
\hline \multirow{4}{*}{$\begin{array}{l}\text { Antisymmetric } \\
\text { laminate } \\
\text { sequence }\end{array}$} & \multirow{4}{*}{$\begin{array}{l}\text { Mode } \\
\text { number }\end{array}$} & \multicolumn{8}{|c|}{ Non-dimensional frequency coefficients $\left(K_{f}\right)$} \\
\hline & & \multicolumn{8}{|c|}{ Aspect ratio $(a / b)$} \\
\hline & & \multicolumn{2}{|c|}{1.0} & \multicolumn{2}{|c|}{1.5} & \multicolumn{2}{|c|}{2.0} & \multicolumn{2}{|c|}{2.5} \\
\hline & & Exp & FEM & Exp & FEM & Exp & FEM & Exp & FEM \\
\hline \multirow{3}{*}{ Angle ply $0^{\circ}$} & 1 & 16.014 & 16.595 & 15.812 & 16.557 & 15.543 & 16.448 & 15.314 & 16.379 \\
\hline & 2 & 16.999 & 17.616 & 17.909 & 18.753 & 18.955 & 20.058 & 20.203 & 21.608 \\
\hline & 3 & 21.958 & 22.755 & 30.296 & 31.723 & 41.246 & 43.646 & 42.345 & 45.289 \\
\hline \multirow{3}{*}{ Angle ply $\pm 45^{\circ}$} & 1 & 12.972 & 13.442 & 12.003 & 12.569 & 11.117 & 11.764 & 10.461 & 11.188 \\
\hline & 2 & 14.369 & 14.890 & 16.867 & 17.662 & 19.881 & 21.038 & 22.708 & 24.286 \\
\hline & 3 & 23.764 & 24.626 & 33.427 & 35.002 & 33.081 & 35.006 & 32.189 & 34.426 \\
\hline \multirow{3}{*}{ Angle ply $90^{\circ}$} & 1 & 8.892 & 9.214 & 8.474 & 8.873 & 8.079 & 8.549 & 7.780 & 8.321 \\
\hline & 2 & 10.655 & 11.042 & 11.900 & 12.461 & 13.312 & 14.087 & 14.902 & 15.938 \\
\hline & 3 & 20.408 & 21.149 & 23.573 & 24.683 & 22.761 & 24.085 & 22.164 & 23.705 \\
\hline \multirow{3}{*}{$\begin{array}{l}\text { Cross-ply } \\
0^{\circ} / 90^{\circ}\end{array}$} & 1 & 13.020 & 13.492 & 12.778 & 13.380 & 12.488 & 13.215 & 12.242 & 13.093 \\
\hline & 2 & 14.555 & 15.082 & 15.690 & 16.429 & 16.832 & 17.811 & 18.175 & 19.439 \\
\hline & 3 & 23.111 & 23.949 & 34.105 & 35.712 & 34.522 & 36.531 & 33.954 & 36.314 \\
\hline
\end{tabular}


Table 5. Non-dimensional frequencies of laminated composite skew plate (skew- $45^{\circ}$ ).

\begin{tabular}{|c|c|c|c|c|c|c|c|c|c|}
\hline \multirow{4}{*}{$\begin{array}{l}\text { Antisymmetric } \\
\text { laminate } \\
\text { sequence }\end{array}$} & \multirow{4}{*}{$\begin{array}{l}\text { Mode } \\
\text { number }\end{array}$} & \multicolumn{8}{|c|}{ Non-dimensional frequency coefficients $\left(K_{f}\right)$} \\
\hline & & \multicolumn{8}{|c|}{ Aspect ratio $(a / b)$} \\
\hline & & \multicolumn{2}{|c|}{1.0} & \multicolumn{2}{|c|}{1.5} & \multicolumn{2}{|c|}{2.0} & \multicolumn{2}{|c|}{2.5} \\
\hline & & Exp & FEM & Exp & FEM & Exp & FEM & Exp & FEM \\
\hline \multirow{3}{*}{ Angle ply $0^{\circ}$} & 1 & 18.149 & 18.711 & 17.719 & 18.457 & 17.593 & 18.137 & 17.515 & 17.872 \\
\hline & 2 & 19.284 & 20.087 & 20.491 & 21.570 & 21.794 & 23.186 & 23.288 & 25.040 \\
\hline & 3 & 26.964 & 28.087 & 37.360 & 39.327 & 46.893 & 49.887 & 46.186 & 49.662 \\
\hline \multirow{3}{*}{ Angle ply $\pm 45^{\circ}$} & 1 & 17.949 & 18.697 & 16.312 & 17.171 & 14.077 & 14.975 & 12.561 & 13.506 \\
\hline & 2 & 18.365 & 19.130 & 19.842 & 20.886 & 23.149 & 24.627 & 26.238 & 28.213 \\
\hline & 3 & 28.674 & 29.869 & 37.477 & 39.449 & 43.781 & 46.576 & 40.812 & 43.884 \\
\hline \multirow{3}{*}{ Angle ply $90^{\circ}$} & 1 & 13.011 & 13.554 & 11.513 & 12.119 & 10.253 & 10.907 & 9.411 & 10.119 \\
\hline & 2 & 14.626 & 15.235 & 15.792 & 16.623 & 17.033 & 18.121 & 18.577 & 19.976 \\
\hline & 3 & 25.705 & 26.776 & 30.856 & 32.480 & 29.319 & 31.190 & 27.562 & 29.636 \\
\hline \multirow{3}{*}{$\begin{array}{l}\text { Cross-ply } \\
0^{\circ} / 90^{\circ}\end{array}$} & 1 & 16.062 & 16.731 & 15.304 & 16.109 & 14.547 & 15.475 & 13.928 & 14.976 \\
\hline & 2 & 17.989 & 18.739 & 19.401 & 20.422 & 20.551 & 21.863 & 21.952 & 23.604 \\
\hline & 3 & 29.705 & 30.943 & 39.355 & 41.427 & 40.157 & 42.721 & 38.893 & 41.820 \\
\hline
\end{tabular}

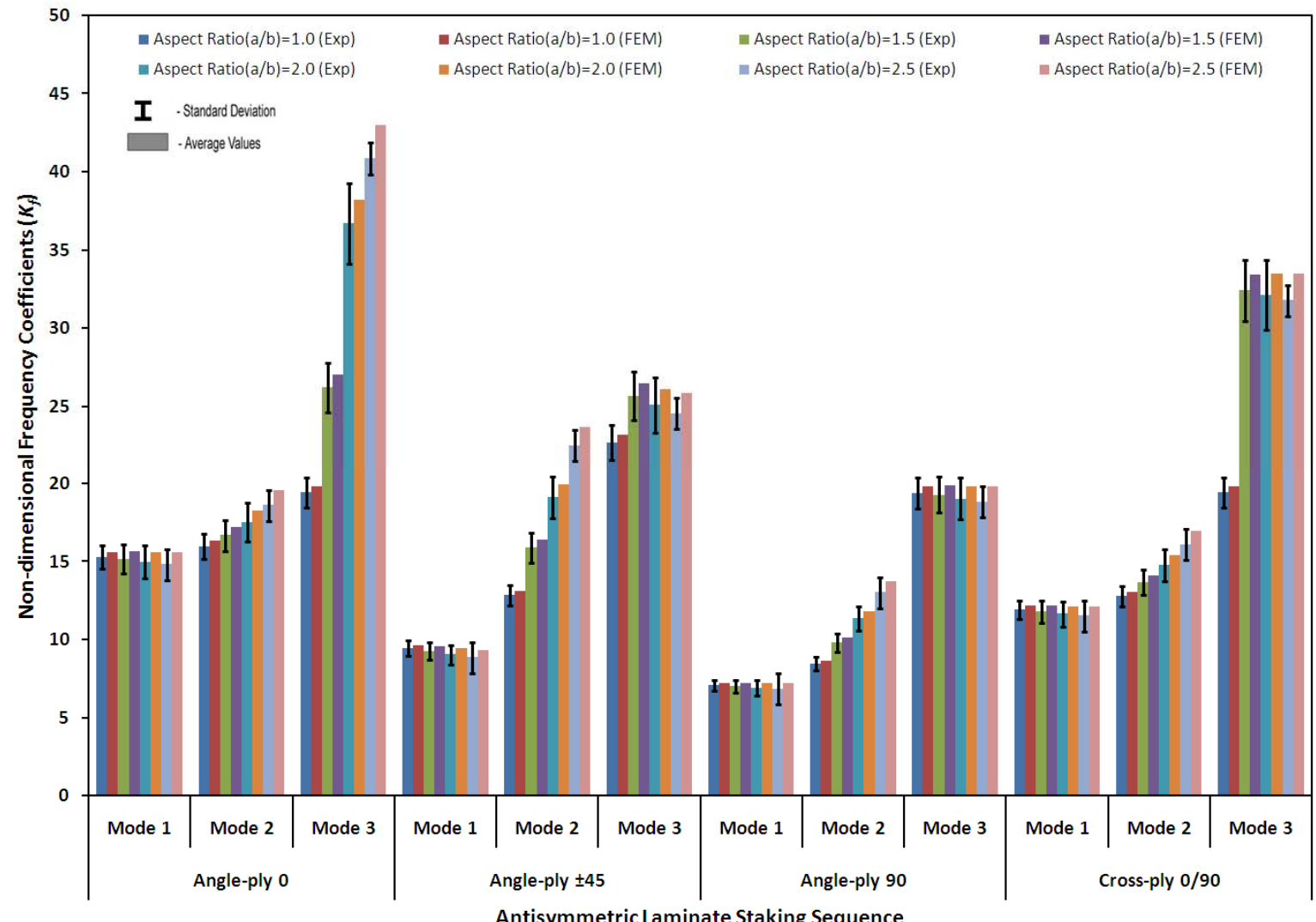

Fig.4. Variations of $K_{f}$ with the aspect ratio $(a / b)$ and laminate stacking sequence for laminated composite skew plates $\left(\alpha=0^{\circ}\right)$. 


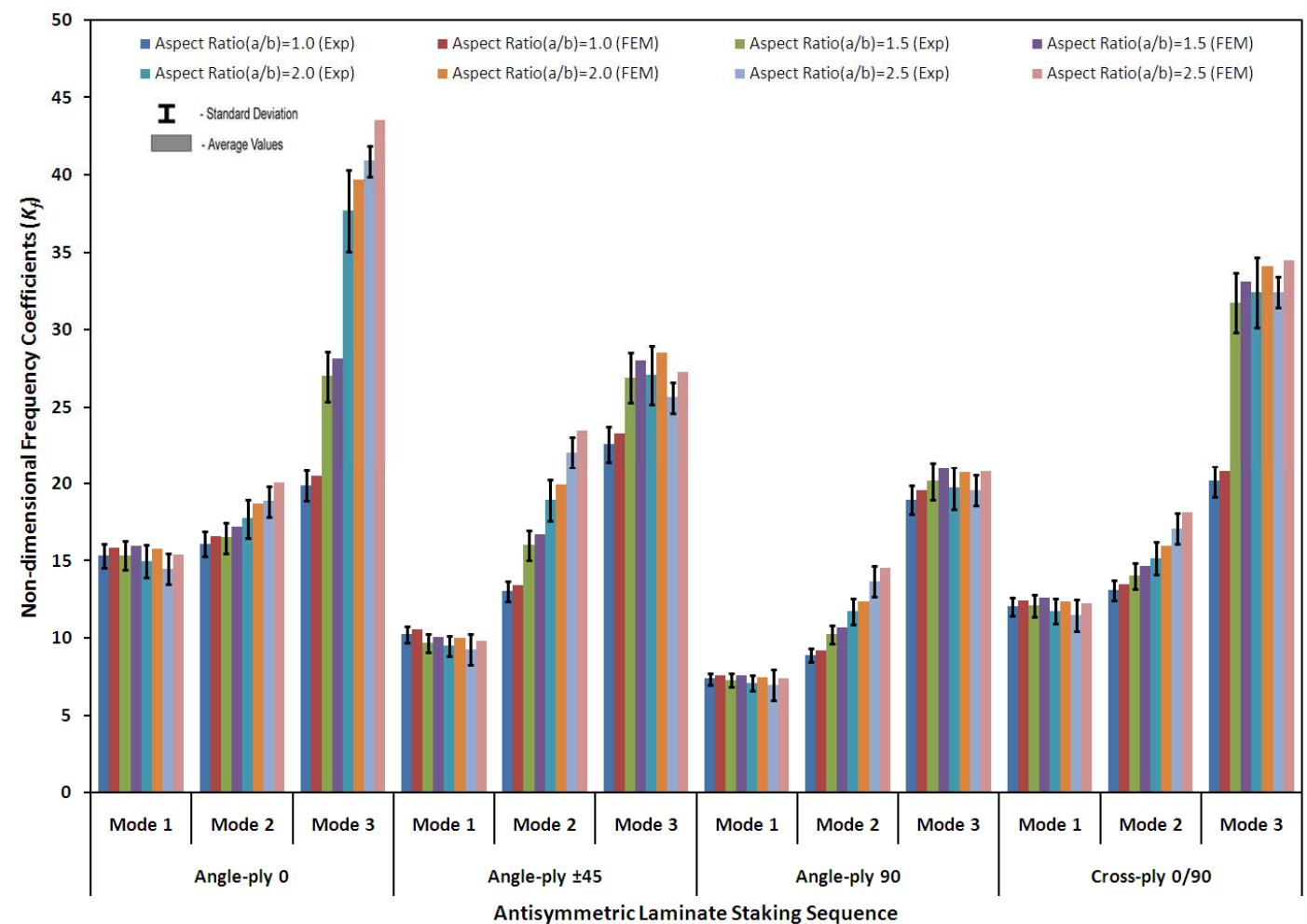

Fig.5. Variations of $K_{f}$ with the aspect ratio $(a / b)$ and laminate stacking sequence for laminated composite skew plates $\left(\alpha=15^{\circ}\right)$.

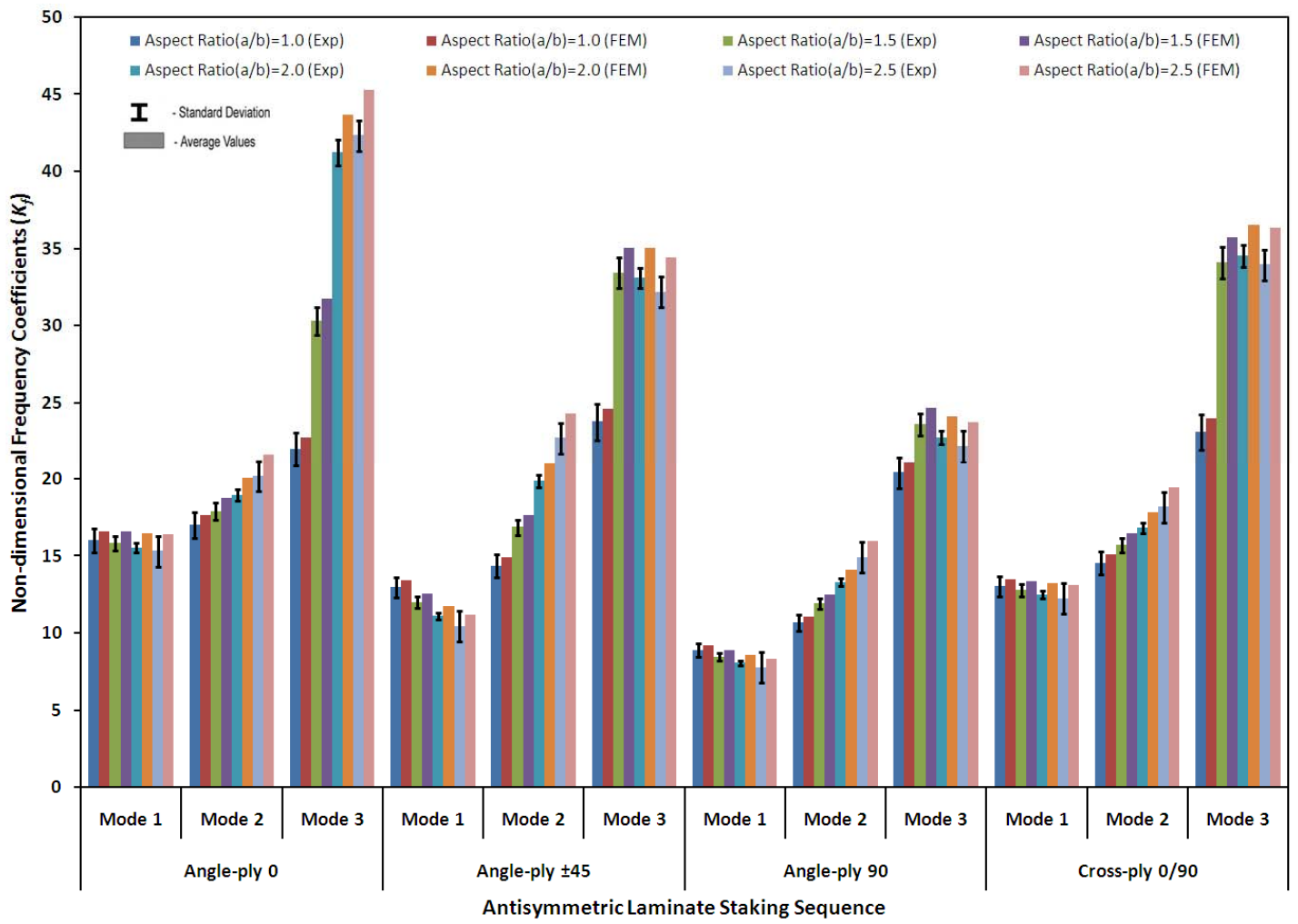

Fig.6. Variations of $K_{f}$ with the aspect ratio $(a / b)$ and laminate stacking sequence for laminated composite skew plates $\left(\alpha=30^{\circ}\right)$. 


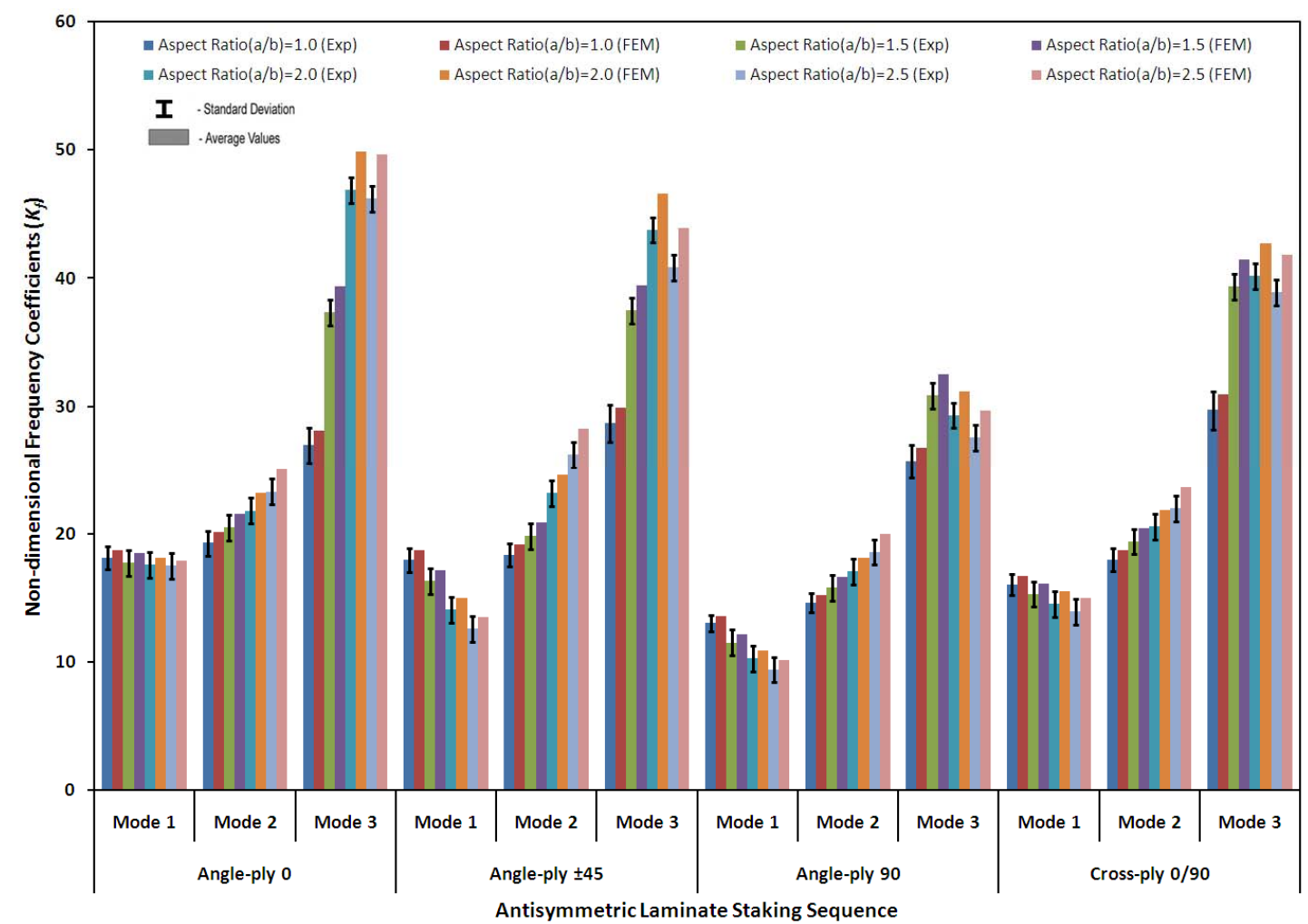

Fig.7. Variations of $K_{f}$ with the aspect ratio $(a / b)$ and laminate stacking sequence for laminated composite skew plates $\left(\alpha=45^{\circ}\right)$.

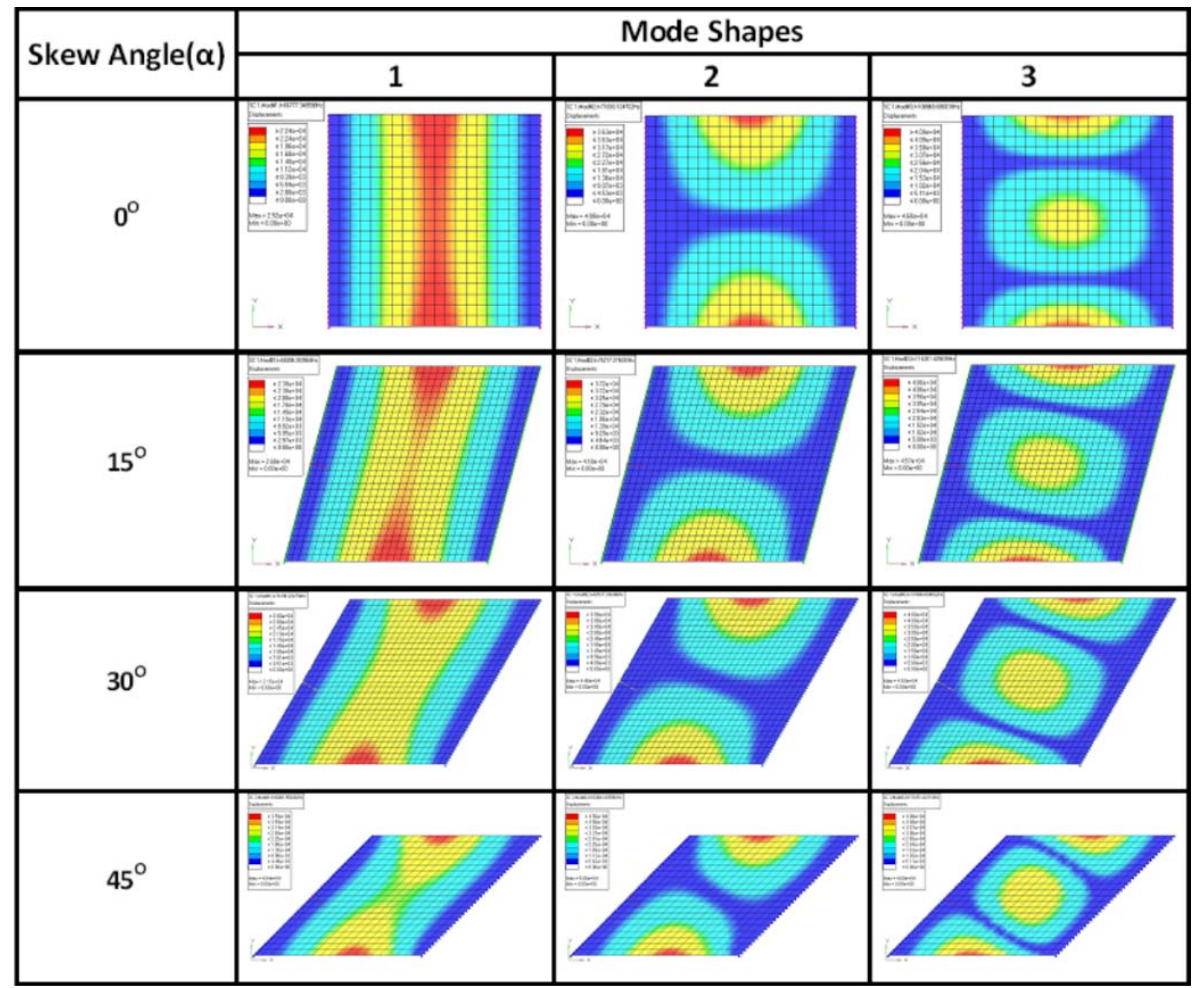

Fig.8. Mode shapes for laminated composite skew plates $(a / b=1.0, N L=20$, antisymmetric cross-ply laminates). 


\section{Conclusions}

The following conclusions are made based on the above study.

- The experimental values of the natural frequencies agree well with the FE solutions both in the case of isotropic and laminated composite skew plates.

- The variation of natural frequencies with the aspect ratio is small and negligible both in the case of isotropic and laminated composite skew plates.

- The natural frequencies increase with an increase in the skew angle, the increase being considerable in the case of isotropic skew plates and small for laminated composite skew plates.

- This study sheds more light on free vibration characteristics of laminated composite skew plates in particular.

\section{Acknowledgments}

The first author would like to thank the Management and Principal of GM Institute of Technology, Davangere, Karnataka, India for the kind encouragement and support provided. The second author would like to thank the Management of Jawaharlal Nehru College of Engineering, Shivamogga, Karnataka, India for the kind encouragement and support provided. The third author would like to thank the Management, Principal and Head of the Department of Civil Engineering, Reva Institute of Technology and Management, Bangalore, Karnataka, India for the kind encouragement and support provided.

\section{Nomenclature}

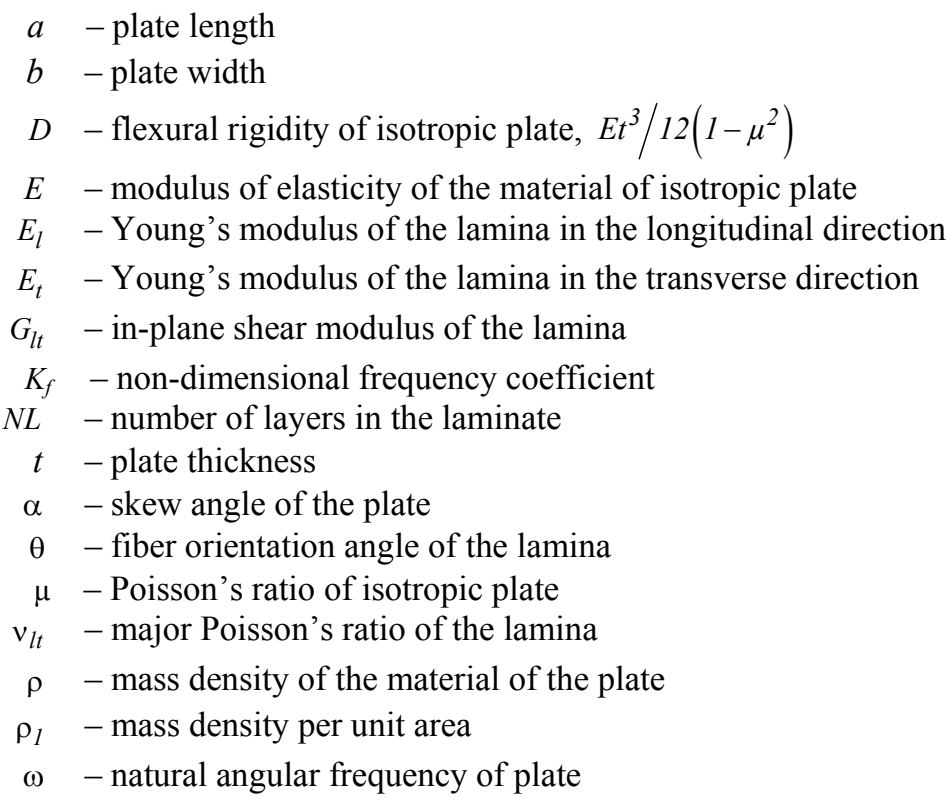

\section{References}

Bardell N.S. (1992): The free vibration of skew plates using the hierarchical finite element method. - Computer and Structures, vol.45, pp.841-874.

Barton M.V. (1951): Vibration of rectangular and skew cantilever plates. - Journal of Applied Mechanics, ASME, vol.18, pp.129-134. 
Cawley P. and Adams R.D. (1978): The predicted and experimental natural modes of free-free CFRP plates. - Journal of Composite Materials, vol.12, pp.336-347.

Chakraborty S., Mukhopadhyay M. and Mohanty A.R. (2000): Free vibrational responses of FRP composite plates: Experimental and numerical studies. - Journal of Reinforced Plastics and Composites, vol.19, pp.535-551.

Clary R.L. (1975): Vibration characterstics of aluminium plates reinforced with boron-epoxy composite material. Journal of Composite Materials, vol.7, pp.348-365.

Classen R.W. (1963): Vibration of skew cantilever plates. - American Institute of Aeronautics and Astronautics Journal, vol.1, pp.1222-1228.

Conway H.D. and Farnham K.A. (1965): The free flexural vibrations of triangular rhombic and parallelogram plates and some analogies. - International Journal of Mechanical Sciences, vol.7, pp.811-816.

Durvasula S. (1969): Natural frequencies and modes of clamped skew plates. - American Institute of Aeronautics and Astronautics Journal, vol.7, pp.1164-1166.

Dutt K.M. and Shivanand H.K. (2011): An experimental approach to free vibration response of carbon composite laminates. - Journal of Advanced Engineering and Applications, pp.66-68.

Garg A.K., Khare R.K. and Kant T. (2006): Free vibration of skew fiber-reinforced composite and sandwich laminates using a shear deformable finite element model. - Journal of Sandwich Structures and Materials, vol.8, pp.33-53.

Hamada M. (1959): Compressive or shearing buckling load and fundamental frequency of a rhomboidal plate with all edges clamped. - Bulletin of JSME, vol.2, pp.520-526.

Hasegawa M. (1957): Vibration of clamped parallelogrammic isotropic flat plates. - Journal of Aeronautical Sciences, vol.24, pp.145-146.

Kamal K. and Durvasula S. (1986): Some studies on free vibration of composite laminates. - Composite Structure, vol.5, pp.177-202.

Kaul R.M. and Cadambe V. (1956): The natural frequencies of thin skew plates. - Aeronautical Quarterly, vol.7, pp.37352.

Krishna Reedy A.R. and Palaninathan R. (1999): Free vibration of skew laminates. - Computers and Structures, vol.70, pp.415-423.

Krishnan A. and Deshpande J.V. (1992): Vibration of skew laminates. - Journal of Sound and Vibrations, vol.153, No.2, pp.351-358.

Kuttler J.R. and Sigillito V.G. (1980): Upper and lower bounds for frequencies of clamped rhombical plates. - Journal of Sound and Vibration, vol.68, pp.597-607.

Laura P.A. and Grosson J. (1968): Fundamental frequency of vibration of rhombic plates. - Journal of Acoustical Society of America, vol.44, pp.823-824.

Liew K.M. and Lam K.Y. (1990): Application of two-dimensional orthogonal plate functions to flexural vibration of skew plates. - Journal of Sound and Vibration, vol.132, No.2, pp.241-252.

Liew K.M. and Wang C.M. (1993): Vibration studies on skew plates: treatment of internal line supports. - Computers and Structures, vol.49, No.6, pp.941-951.

Malhotra S.K., Ganesan N. and Veluswami M.A. (1988): Effect of fiber orientation and boundary conditions on the vibration behavior of orthotropic rhombic plates. - Journal of Composites, vol.19, No.2, pp.127-132.

Maruyama K., Ichinomiya O. and Narita Y. (1983): Experimental study of the free vibration of clamped trapezoidal plates. - Journal of Sound and Vibration, vol.88, No.4, pp.523-534.

McGee O.G. and Butalia T.S. (1994): Natural frequencies of shear deformable cantilevered skew thick plates. - Journal of Sound and Vibrations, vol.176, pp.351-376.

Mizusawa T. and Kajita T. (1986): Vibration and buckling of skew plates with edges elastically restrained against rotation. - Computers and Structures, vol.22, pp.987-994. 
Mizusawa T. and Kajita T. (1987): Vibration of skew plates resting on point supports. - Journal of Sound and Vibration, vol.115, pp.243-251.

Mizusawa T., Kajita T. and Naruoka M. (1979): Vibration of skew plates by using b-spline functions. - Journal of Sound and Vibration, vol.62, pp.301-308.

Mizusawa T., Kajita T. and Naruoka M. (1980): Analysis of skew plate problems with various constraints. - Journal of Sound and Vibration, vol.68, pp.575-584.

Monforton G.R. (1968): Finite element displacement and vibration analysis of skew plates. - Report18, Division of Solid Mechanics. Structural and Mechanical Design Case. - Cleveland, Ohio: Western Reserve University.

Nair P.S. and Durvasula S. (1973): Vibration of skew plates. - Journal of Sound and Vibration, vol.26, No.1, pp.1-19.

Singh B. and Chakraverthy S. (1994): Flexural vibration of skew plates using boundary characteristic orthogonal polynomials in two variables. - Journal of Sound and Vibrations, vol.173, pp.157-178.

Singha M.K. and Ganapathi M. (2004): Large amplitude free flexural vibrations of laminated skew plates. - Journal of Non-Linear Mechanics, vol.39, pp.1709-1720.

Srinivasa C.V., Suresh Y.J. and Prema Kumar W.P. (2012): Free flexural vibration studies on laminated composite skew plates. - International Journal of Engineering, Science and Technology, vol.4, No.4, pp.13-24.

Srinivasan R.S. and Ramachandran S.V. (1975): Vibration of generally orthotropic skew plates. - Journal of Acoustic Society of America, vol.57, pp.1113-1118.

Thangam Babu P.V. and Reddy D.V. (1971): Frequency analysis of skew orthotropic plates by the finite strip method. Journal of Sound and Vibration, vol.18, No.4, pp.465-474.

Received: August 20, 2013

Revised: October 9, 2013 